\title{
Pluralism in Search of Sustainability: Ethics, Knowledge and Methdology in Sustainability Science
}

\author{
Ellinor Isgren ${ }^{1,2}$, Anne Jerneck ${ }^{1,2, *}$ and David O’Byrne ${ }^{1,2}$ \\ ${ }^{1}$ Lund University Centre for Sustainability Studies (LUCSUS), Lund, Sweden \\ ${ }^{2}$ Lund University Centre of Excellence for Integration of Social and Natural Dimensions of Sustainability, Lund, Sweden \\ * Corresponding author: E-Mail: anne.jerneck@lucsus.lu.se; Tel.: +46 462220512 \\ Published: 13 February 2017
}

Sustainability Science is an emerging, transdisciplinary academic field that aims to help build a sustainable global society by drawing on and integrating research from the humanities and the social, natural, medical and engineering sciences. Academic knowledge is combined with that from relevant actors from outside academia, such as policy-makers, businesses, social organizations and citizens. The field is focused on examining the interactions between human, environmental, and engineered systems to understand and contribute to solutions for complex challenges that threaten the future of humanity and the integrity of the life support systems of the planet, such as climate change, biodiversity loss, pollution, and land and water degradation. Since its inception in around the year 2000, and as expressed by a range of proponents in the field, sustainability science has become an established international platform for interdisciplinary research on complex social problems [1]. This has been done by exploring ways to promote 'greater integration and cooperation in fulfilling the sustainability science mandate' [2]. Sustainability science has thereby become an extremely diverse academic field, yet one with an explicit normative mission. After nearly two decades of sustainability research, it is important to reflect on a major question: what critical knowledge can we gain from sustainability science research on persistent socio-ecological problems and new sustainability challenges?

As a step in that direction, we solicited submissions to a special issue on Sustainability Science in the open access journal Challenges in Sustainability (CiS). Whilst the question above will not be sufficiently answered in this special issue, what is provided are some examples of what sustainability science can offer and how parallels can be drawn with other study areas dealing with issues of sustainability. As direction for the issue and as inspiration for authors, we asked them to reflect on the field's mission, achievements and conflicts. To complement more systematic assessments such as literature reviews, we hope that this type of exercise can be a recurrent one, as a way to continually spur active reflection among scholars in the field.

\section{Reflecting on the Evolving Characteristics of Sustainability Science}

Sustainability science seeks knowledge integration across disciplines, domains and scales including the natural and social sciences, nature-society, sciencesociety and knowledge-to-action. The quest to produce knowledge and expertise on global sustainability challenges while working actively to reduce the distances between disciplines, theory and practice is what most distinguishes it from other fields [3]. These ambitions have led to specific criteria being proposed, for example that sustainability science should be salient in focus and findings, credible in data and methods, and legitimate in outreach and solution options, as stated early on by Cash et al. [4]. In a further step to describe the mission of the field, proponents have emphasized that sustain- 
ability science is defined more by the problems it studies and the type of solutions it seeks-rather than by its disciplinary content [5]. In that respect the field is often defined by its research purpose, its applicability, and our roles as reflexive researchers [6]. This explains why proponents stress the constructive, normative and transformational attributes of the field along with the core values of integrity, justice, and viability $[7,8]$. Furthermore there is agreement that to match the ambition of being problem-based and solution-oriented, the process of knowledge production within sustainability science is to be characterized by collaborative approaches in the form of interdisciplinary or even transdisciplinary research [9]. To that end, it builds on several foundational disciplines and employs methodological pluralism. Variety in perspectives is crucial for understanding how multiple persistent social problems interact with new sustainability challenges $[9,10]$. Concepts like socioecological system and transition management are used as theoretical frames and foundations to bridge and better understand different but interrelated problem areas [11]. Sustainability science also goes beyond these frames to engage with critical theory and other perspectives necessary for bridging the boundaries between disciplines, social and natural systems, science and society, and knowledge and action [4,11].

All of these characteristics contribute to clarify the mission and mandate of sustainability science, but also increase the demands on the field thus making it difficult to grasp in its entirety [12]. By continuously integrating previously separate research problems and methodologies, the landscape of sustainability science is rapidly changing and expanding $[11,13]$. Reflecting on this process, some scholars are partly critical of the extent to which the field's aspired characteristics have materialized; Wiek et al. [7] for example, claim that sustainability science fails to make sufficient and significant contributions to potential options for transformational change, and [9] point to a discrepancy between promises to provide solutions and the actual delivery. These must be taken seriously. Others argue that both interdisciplinarity and transdisciplinarity in sustainability science are making progress, albeit the latter at a slower pace [11]. Why is this type of reflexive debate important? Some argue that sustainability science emerged as a revolutionary concept in the Kuhnian sense [14,15], referring to how the field responded to the scientific crisis in the normal sciences which could neither deal appropriately with the complexity of the new sustainability challenges nor bridge the sciencesociety divide. Although this may be contested, it is widely acknowledged that sustainability science aspires to a new mode of knowledge production $[6,16,17]$. Given this ambitious agenda, including core questions, announced at the field's inception and followed by a rapid expansion that has also added new dimensions to this agenda, scholars need to engage in continuous assessment of sustainability science as a field-both challenges that remain, and achievements that point to promising ways forward.

\section{Introducing the Contributions to This Special Issue}

\subsection{How Can Transformative Processes of Knowledge Co-Production and Partnership Be Designed}

How do we need to proceed as researchers if we think that sustainability science should progress in ways that matter to people? Many scholars advocate pluralism in pursuing this task $[18,19]$. It implies that we should use approaches in sustainability science that take various forms of knowledge into consideration even if this can give rise to new challenges. As an example, efforts to integrate western science with indigenous knowledge may run into difficulties if they clash either in worldviews or in forms of knowledge production-or in both. To overcome this, and to support a wider sustainability agenda that takes both time and scale seriously, we may follow Meg Parsons et al. in their call for environmental ethics that help recognize the influence that colonialism and environmental determinism have in shaping views on and for sustainability. In doing so we must consider the underlying aims of research, how it is designed, how the dynamics between past and present is studied, and how communities that we do research with and for (rather than on) are defined, framed and represented. To illustrate this, Parsons et al. discuss insights from a case study on Waipā River in New Zealand where an indigenous community successfully renegotiated and enacted new approaches to tackle several socio-ecological crises. In that process, knowledge sharing and mutual learning were appreciated, practiced and found useful.

In another case study, Cordula Ott persuasively illustrates how North-South collaboration across the sciencesociety divide can promote and provide transformative knowledge, and how the notion of sustainable development in itself has integrative potential when used as a shared frame of reference by the different actors involved. Over a fifteen year period, this partnership program, based on meaningful participation, interaction and agency, generated context-based knowledge and innovations for sustainability while also taking into account local needs. Ott emphasizes that transdisciplinary practice in the context of North-South research partnerships is a complex process that requires long-term commitment, adaptiveness, and particular attention to Southern partners' capacity and ownership.

\subsection{How Can Film as a Medium Serve The Purpose of Knowledge Integration and Distribution?}

It is an oft-spoken ambition in sustainability science to combine critical analysis with problem solving activities [20]. For that purpose researchers may take a critical theory approach to inform the substance and process of dialogue with citizens and communities who have a stake in certain socio-ecological matters. Multiple strategies, methods and techniques can be used in such a dialogue, sometimes taking the form of a real co-production of knowledge, including social learning. The film that Elina Andersson and Ann 
Ákerman produced in collaboration with small-scale farmers in Uganda, is a perfect illustration of how academic and local knowledge can be fused and also aligned with a suitable outreach strategy. In the film we learn about causes and consequences of land degradation and soil nutrient depletion and how problems of low agricultural productivity can be tackled and partially overcome in a setting of food insecurity.

\subsection{Sustainability Science and Urban Planning-How Can We Foster Mutual Learning?}

Also in line with the ambition to foster interdisciplinarity and knowledge integration, sustainability scientists can point to opportunities for scholars and practitioners in neighbouring fields to benefit from work done within sustainability science, and vice versa. Concerned with both continuity and change in the search of sustainability, François Mancebo argues that as part of its mission, sustainability science can help change the way urban planners think about and engage with urban problems. Given that effective standard planning may not be either possible or relevant for sustainability, urban planners should be flexible and continuously consider contextual and long-term consequences of decisions, policies and technology change. In order to understand how change is received by and responded to, planners should build effective action on the basis of collaborative planning together with interests in society-both organizations and civil society.

\subsection{What Kinds of Methodology Are Appropriate for Solutions-Oriented Research In a Complex World?}

Henrik von Wehrden et al., like Mancebo, conceptualize the problems that Sustainability Science seeks to treat as wicked problems. They do so in order to tease out some of the methodological and knowledge integration challenges that complexity and solutions-orientation generate. Suitable methodologies, they show, ought to be at once flexible and precise: they must consider a variety of different approaches while at the same time employing firm procedural and ethical guidelines. The authors close with a call for longer-term research projects and longitudinal designs to track the development and shifting of sustainability problems over time.

\subsection{Are There Ways to Address the Challenges of Contradicting Norms and Value Based Dilemmas?}

Sustainability problems are often described as deeply normative $[1,21]$ both in the sense that sustainable development itself is a normative goal and that competing norms in society need to be understood and considered as part of research in sustainability science [22]. In a paper on competing norms and contradictory principles, Tim O'Higgins takes environmental legislation in the EU as a case to illustrate how directives and legislation are embedded in both past and present norms, and how a more proactive and transformative approach is required to halt biodiversity loss. O'Higgins examines how biodiversity norms are translated into three types of environmental policies-Practical, Popular and Pure - which vary in the approach to biodiversity and environmental protection. Importantly, they display a particular tension between giving priority to the practical provision of food versus ensuring pure protection of nature. Here the use of the concept ecosystem services may help resolve some of the tensions.

\subsection{Education for Sustainability -What Are the Best Criteria and Methods to Continually Assess Field Based Courses?}

There is a call for educational programs at all levels to foster the next generation of sustainability professionals both within and outside of academia [23]. To make the most of such programmes, course designers and teachers must consider both content and instruction format, and establish quality criteria and procedures to continually assess how well education meets the requirements of sustainability and the need for social change. In their study, Ricardo San Carlos et al. focus on procedures to assess problem-driven approaches in educational programmes in sustainability science. They do so-specifically in field based courses and by using the criteria of the 'five key competencies' [24] serving to increase students' awareness of their future roles in science and society. Although this set of criteria may function well as a basis, they recommend that we go beyond them in further assessments to include other aspects that are pertinent to sustainability science education.

\section{Applying Plurality in Perspectives, Procedures and Values as a Way Forward}

What are the principal achievements, persistent challenges and pathways forward in sustainability science, as reflected by the snapshot of the field presented in this special issue's articles? Some clear themes emerge; some we recognize from the mission for sustainability science, which were set out in the founding work of the field. Other themes represent familiar challenges to those who do research in and teach sustainability science; these have become more apparent as the field has developed. The themes notably connect to different kinds of plurality, and describe domains where considerable progress has been made, sites of ongoing struggles, and indications of promising avenues for future research in this burgeoning field.

\subsection{Knowledge Integration}

There is agreement that sustainability science is supposed to take an integrated, comprehensive and participatory approach [15]. As such, sustainability science seeks knowledge integration across disciplines, domains and scales $[9,20]$. A number of articles in this issue deal with different aspects of this broad question of knowledge integration. 
Mancebo discusses the mutual learning and benefits that can occur between fields or disciplines concerned with solving complex problems, while both Ott and Parsons et al. deal with the incorporation of different forms of knowledge, with the latter highlighting the ethical dilemmas involved. Andersson and Åkerman cross both the science-society and the knowledge-to-action gap, using film as medium for both dissemination and transformation. Looking to the future, we are reminded to remain vigilant about how we achieve integration between disparate forms of knowledge. At the same time, we are challenged to make more conscious efforts to engage systematically with what may seem to be unexpected disciplines, and to use creative methods like non-traditional media, which can not only facilitate more useful dissemination but also contribute to transformative processes.

\subsection{Ongoing Methodological Challenges}

The challenge of knowledge integration across many conventional 'gaps', though recognized early on, was perhaps underestimated in terms of understanding what approaches and methodologies would be effective, both for research and learning. In this issue, von Wehrden et al., speaking of sustainability science research in general, deal with the tension between the need for pluralism and flexibility on the one hand and the requirement for precision in methodological approaches on the other. In relation to teaching and learning sustainability, San Carlos et al. investigate the best methods and criteria for evaluating non-traditional problem-based field courses, proposing a continued and broadened focus on such evaluation in the future. That the methodological challenge was initially underestimated should spur us forward, to continue critical discussions but more importantly to dare to innovate, to investigate the variety of forms that pluralism can take, both in research and in the classroom, and to discover what knowledge and understandings such pluralism can produce.

\subsection{Dealing with a Plurality of Values}

Lafferty pointed out 20 years ago that sustainability transitions are normative actions [25]. Social and political theory has struggled for centuries with conceptualizing the causes and effects of a plurality of values in society, as seen by, Hobbes, Rousseau and many more, and so it is a subject not likely to be settled anytime soon. Nevertheless, two of the articles herein suggest how we might address this plurality more directly when it comes to the specific challenges of sustainability science. As mentioned earlier, Parsons et al. employ an ethical approach as a means to mediate between discrete forms of knowledge. O'Higgins, on the other hand, in a piece on European biodiversity policy, makes the norms entailed in policies the subject of theoretical investigation, with the intention of solving value-centred dilemmas. While the question of normativity has been central to sustainability science since its inception, the articles here provide a glimpse of the wealth of approaches within the social sciences and humanities, which has not yet been fully exploited. This is an inspiring challenge for up and coming interdisciplinary and transdisciplinary researchers.

\section{References and Notes}

[1] Miller TR. Constructing sustainability science: emerging perspectives and research trajectories. Sustainability Science. 2013;8(2):279-293. doi:10.1007/s11625-012-0180-6.

[2] Kauffman J, Arico S. New directions in sustainability science: Promoting integration and cooperation. Sustainability Science. 2014;9(4):413-418. doi:10.1007/s11625-014-0259-3.

[3] Kates RW, Clark WC, Corell R, Hall JM, Jaeger CC, Lowe I, et al. Sustainability Science. Science. 2001;292(5517):641-642. doi:10.2139/ssrn.257359.

[4] Cash DW, Clark WC, Alcock F, Dickson NM, Eckley N, Guston DH, et al. Knowledge systems for sustainable development. Proceedings of the National Academy of Sciences. 2003;100(14):8086-8091. doi:10.1073/pnas.1231332100.

[5] Clark WC. Sustainability science: A room of its own. Proceedings of the National Academy of Sciences. 2007;104(6):1737. doi:10.1073/pnas.0611291104.

[6] Spangenberg JH. Sustainability science: A review, an analysis and some empirical lessons. Environmental Conservation. 2011;38(03):275-287. doi:10.1017/s0376892911000270.

[7] Wiek A, Ness B, Schweizer-Ries P, Brand FS, Farioli F. From complex systems analysis to transformational change: A comparative appraisal of sustainability science projects. Sustainability Science. 2012;7(1):5-24. doi:10.1007/s11625-011-0148-y.

[8] Wiek A, Iwaniec D. Quality criteria for visions and visioning in sustainability science. Sustainability Science. 2014;9(4):497-512. doi:10.1007/s11625-013-0208-6.

[9] Stock P, Burton RJF. Defining Terms for Integrated (Multi-Inter-Trans-

Disciplinary) Sustainability Research. Sustainability. 2011;3(8):10901113. doi:10.3390/su3081090.

[10] Jerneck A, Olsson L. Breaking out of sustainability impasses: How to apply frame analysis, reframing and transition theory to global health challenges. Environmental Innovation and Societal Transitions. 2011;1(2):255-271. doi:10.1016/j.eist.2011.10.005.

[11] Kajikawa Y, Tacoa F, Yamaguchi K. Sustainability science: The changing landscape of sustainability research. Sustainability Science. 2014;9(4):431-438. doi:10.1007/s11625-014-0244-x.

[12] Kajikawa Y. Research core and framework of sustainability science. Sustainability Science. 2008;3(2):215-239. doi:10.1007/s11625-0080053-1.

[13] Kajikawa Y, Ohno J, Takeda Y, Matsushima K, Komiyama H. Creating an academic landscape of sustainability science: An analysis of the citation network. Sustainability Science. 2007;2(2):221-231. doi:10.1007/s11625-007-0027-8.

[14] Kuhn TS. The structure of scientific revolutions. Chicago, IL, USA: University of Chicago Press; 2012.

[15] Sala S, Farioli F, Zamagni A. Progress in sustainability science: lessons learnt from current methodologies for sustainability assessment: Part 1. The International Journal of Life Cycle Assessment. 2013;18(9):1653-1672. doi:10.1007/s11367-012-0508-6.

[16] Martens P. Sustainability: Science or fiction? Sustainability: Science, Practice, \& Policy. 2006;2(1). doi:10.1109/EMR.2007.4296430.

[17] Thorén H, Breian L. Stepping stone or stumbling block? Mode 2 knowledge production in sustainability science. Studies in History and Philosophy of Science Part C: Studies in History and Philosophy of Biological and Biomedical Sciences. 2016;56:71-81. doi:10.1016/j.shpsc.2015.11.002. 
[18] Thorén H. The Hammer And The Nail [PhD Thesis]. Lund University: Centre for Sustainability Studies. Lund, Sweden; 2015. Available from: https://lup.lub.lu.se/search/publication/e8155748-544c-4b419fa5-3fe3281414be.

[19] Shahadu H. Towards an umbrella science of sustainability. Sustainability Science. 2016;pp. 1-12. doi:10.1007/s11625-016-0375-3.

[20] Jerneck A, Olsson L, Ness B, Anderberg S, Baier M, Clark E, et al. Structuring sustainability science. Sustainability Science. 2011;6(1):69-82. doi:10.1007/s11625-010-0117-x.

[21] Swart RJ, Raskin P, Robinson J. The problem of the future: Sustainability science and scenario analysis. Global Environmental Change. 2004:14(2):137-146. doi:10.1016/j.gloenvcha.2003.10.002.

[22] Lang DJ, Wiek A, Bergmann M, Stauffacher M, Martens P, Moll P, et al. Transdisciplinary research in sustainability science: Practice, principles, and challenges. Sustainability Science. 2012;7(1):25-43. doi:10.1007/s11625-011-0149-x.

[23] Hopkins C, McKeown R. Education for sustainable development: an international perspective. Education and sustainable development Responding to the global challenge Cambridge: IUCN Commission on Education and Communication. 2002;pp. 13-26.

[24] Wiek A, Withycombe L, Redman CL. Key competencies in sustainability: A reference framework for academic program development. Sustainability Science. 2011;6(2):203-218. doi:10.1007/s11625-0110132-6.

[25] Lafferty WM. The politics of sustainable development: global norms for national implementation. Environmental Politics. 1996;5(2):185208. doi:10.1080/09644019608414261. 